\title{
8 Here is an Old Mastiffe Bitch $\varnothing$ Stands Barking at Mee: Zero Subject Relativizers in Early Modern English (T)here-Constructions ${ }^{1}$
}

Gunnel Tottie

The University of Zurich

Christine Johansson

Uppsala University

\section{Introduction}

There are two kinds of zero relativizers - those where the gap functions as direct object, as in (I), and those where the gap functions as subject in the relative clause, as in (2), henceforth ZSR. ${ }^{2}$

(I) I have nothing $\varnothing$ I can call my own.... (Thomas Killigrew, Chit-Chat, I7I9)

(2) There were Seven Horses $\varnothing$ came in. (The Tryal of Ambrose Rookwood, I696)

Our purpose here is to throw light on the use of one of the major types, viz. ZSRs in presentative constructions introduced by there or here, as in (2), in Early Modern English, and to attempt to establish factors that influence the choice of surface or zero variant. The gap will be marked $\varnothing$ throughout.

I We are indebted to participants at the symposium in honor of Nils-Lennart Johannesson in February 2013 and at the ICAME 34 conference, Santiago de Compostela, 22-26 May, 20I3, for constructive comments, especially Holger Diessel, Uwe Vosberg, Lilo Moessner and Yoko Iyeiri. We are also indebted to Hans-Martin Lehmann and Sebastian Hoffmann for helpful comments and technical support.

2 Terminology varies here; the term bare relatives is used by Huddleston \& Pullum (2002: I34, I55). There are also scholars who challenge the classification of zero subject relativizers as relativizers, (e.g. Erdmann I980, Nagucka I980 and Lambrecht I988). We will not enter that discussion here but will use traditional terminology and consider zero relativizers as variants of one relativizer variable.

How to cite this book chapter:

Tottie, G. and Johansson, C. 2015. Here is an Old Mastiffe Bitch Ø Stands Barking at Mee: Zero Subject Relativizers in Early Modern English (T)here-Constructions. In: Shaw, P., Erman, B., Melchers, G. and Sundkvist, P. and Sundkvist, P. (eds) From Clerks to Corpora: essays on the English language yesterday and today. Pp. I $35-\mathrm{I} 53$. Stockholm: Stockholm University Press. DOI: http://dx.doi.org/ıo.I6993/bab.h License: CC-BY. 


\section{ZSRs in Present-Day English}

ZSRs get scant attention in the major grammars of contemporary English. Quirk et al. (I985: I250) consider them to be "of doubtful acceptability" or "slovenly," Biber et al. (1999: 619) assert that they occur in "conversational varieties" or "marginally non-standard usage" and Huddleston \& Pullum (2002:1055) declare that "they fall at the boundary between very informal and non-standard." However, ZSRs are characteristic of many British and American English dialects, as is clear from e.g. Ihalainen (I980), Hackenberg (I98I), van den Eynden (I993: I60) and Kortmann \& Schneider (2004).

Moreover, according to a large-scale quantitative and accountable study by Lehmann (2002), based on the spoken demographic component of the British National Corpus ( 4.2 million words) and on the Longman Spoken American Corpus ( 5 million words), ZSRs account for $\mathrm{I} 3 \%$ of all subject relativizers in British Present-Day English (PDE) but for less, 2.5\%, in American PDE. ${ }^{3}$ Following Shnukal (I98I), Lehmann lists the major types of constructions in PDE as those shown in (3)-(6), adding one residual mixed category of "other" types, listed as (7) (the examples given below are from various sources):

(3) Existential there-constructions : There was a farmer $\varnothing$ had a dog (Lambrecht I988)

(4) Clefts: It was he $\varnothing$ took you out. (Erdmann I980)

(5) Be-constructions: ...they were people $\varnothing$ got in there for the summer...(Lehmann 2002: I7I)

(6) Have-constructions: We had a client $\varnothing$ came in about two weeks ago (Erdmann I980)

(7) Other types: I knew a girl Ø worked in an office...(Shnukal I98I)

Lehmann found the distribution of the five ZSR types shown in Table I.

In both British and American English, existential there-constructions predominate.

3 Accountable studies account for all the constructions where alternative variants could have been used, in this case the relativizers that or which/who as in There is a man who/that/Ø wants to see you. 
Table 1. The use of ZSR constructions in PDE. Based on Lehmann (2002:I72, Table 2).

\begin{tabular}{|c|c|c|c|c|}
\hline \multirow[t]{2}{*}{ Types } & \multicolumn{2}{|c|}{$\begin{array}{l}\text { British English } \\
\text { (I } 58 \text { I subject rel. } \\
\text { clauses) }\end{array}$} & \multicolumn{2}{|c|}{$\begin{array}{l}\text { American English } \\
\text { (374I) subject rel. } \\
\text { clauses) }\end{array}$} \\
\hline & $\mathbf{N}$ & $\%$ & $\mathbf{N}$ & $\%$ \\
\hline Existential there-constructions & I 26 & $61 \%$ & 27 & $29 \%$ \\
\hline Clefts & 25 & I $2 \%$ & 24 & $26 \%$ \\
\hline$B e$-constructions & 8 & $4 \%$ & I4 & I $5 \%$ \\
\hline Have-constructions & I 5 & $7 \%$ & 9 & $10 \%$ \\
\hline Other types & $3 \mathrm{I}$ & I $5 \%$ & 20 & $2 \mathrm{I} \%$ \\
\hline Totals zero subject relatives & 205 & I $3 \%$ & 94 & $2.5 \%$ \\
\hline
\end{tabular}

\section{ZSRs in some previous studies}

Zero relatives have received a fair amount of coverage in diachronic studies of English, but ZSRs have been less well described, although they may be the older type. Both existed in OE, according to several writers (see e.g. van der Auwera I986) but zero objects increased in frequency and are now very common (see e.g. Johansson 20I2; Tottie I997).

Previous studies have either concentrated on the origin of the ZSR and how it decreased from the Old English period and onwards (see e.g. Erdmann I980; Nagucka I980; van der Auwera I984), or have described its use in written data and in other time periods - see e.g. Dekeyser (I984) and Rydén (I966).

Ukaji (2003) is based on all of Shakespeare's plays, three plays by Ben Jonson, and Nashe's The Unfortunate Traveller. In his material, consisting of 303 examples, $40 \%$ of all ZSR instances are either hereor there-constructions, I $4 \%$ are $i t$-clefts, I० $\%$ are have-sentences, and $23 \%$ various other types, thus a distribution not unlike that found by Lehmann for Present-Day English.

Although some earlier historical grammarians have quantified their material, none seem to have carried out accountable studies. Our study appears to be the first diachronic study of ZSRs that is both quantified and accountable. We also aim to pinpoint factors that trigger or constrain the choice of ZSRs, something that has not previously been attempted 
beyond the basic establishment of the major contexts favoring ZSR, i.e. existential (t/here-), cleft, have- and to some extent be-constructions.

\section{Our speech-related data}

As the zero relativizer has been described as colloquial and "spoken" in character (see Erdmann I980; Nagucka I980; Romaine I98 I:94; Dekeyser I986), we will focus on the use of ZSRs in speech-related texts: Trials and Comedy, which have been deemed the most speech-like (cf. Culpeper and Kytö 2000:I86-193).

We studied transcripts of trials and plays from the category Drama/ Comedy in the computerized Corpus of English Dialogues, I 560-I760 (CED) (for a full description of this corpus, see Kytö \& Walker 2006). We will use the term Comedy for simplicity. The material is presented in Table 2:

Table 2. Our CED sub-corpus consisting of Trials and Comedy.

\begin{tabular}{lccc}
\hline CED periods & \multicolumn{1}{c}{ Trials } & Comedy & Totals N words \\
\hline I. I560-I599 & I9,940 & 47,590 & 67,530 \\
2. I600-I639 & I4,430 & 47,700 & $62, \mathrm{I} 30$ \\
3. I640-I679 & $70, \mathrm{I} 90$ & 47,590 & $\mathrm{II} 7,780$ \\
4. I680-I7I9 & 96,630 & 47,200 & $\mathrm{I} 43,830$ \\
5. I720-I760 & 84,650 & $48,5 \mathrm{IO}$ & $\mathrm{I} 33, \mathrm{I} 60$ \\
& 285,840 & 238,590 & 524,430 \\
\hline
\end{tabular}

As appears from Table 2, our sub-corpus amounted to just over half a million words from five successive 40-year time periods between I 560 and I760. It is skewed in several respects: The first two periods contain fewer words than the others because of the scarcity of trial transcripts from the I6th and early I 7 th centuries, but in the following three time periods, Trials account for more material than Comedy, in fact twice as many words in period 4, I680-I7I9. This must be kept in mind when the results are presented.

\section{Method and first results}

We first did a simple lexical search for there, here, it is, and it was (it-clefts); we included here because it had been bundled with there-ex- 
amples by earlier writers (e.g. Jespersen I927: I47; Rydén I966: 267268). We then read the whole corpus to weed out irrelevant material and to find additional types less amenable to lexical searches. We ended up with 2 Io relevant examples, i.e. relativizers in subject function in either $(t)$ here-constructions or clefts, with explicit or zero realizations. We also found I 7 miscellaneous examples where only zero realizations were collected because of problems of finding alternants with surface subject relativizers, as in example (8).

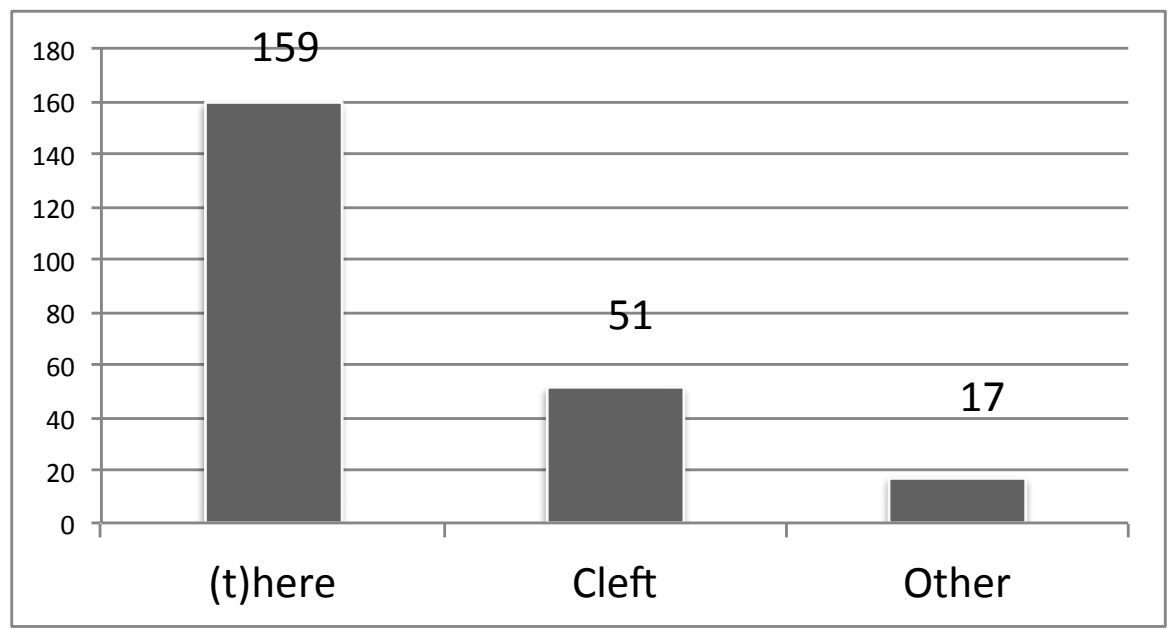

Figure 1. The distribution of constructions capable of taking zero relative constructions in Trials and Comedy in CED.

(8) [Daffodil] Not do it! [hops] Why, I'll get a Chelsea Pensioner $\varnothing$ shall do it in an Hour, with his wooden Leg.

(David Garrick, The Male-Coquette, I757)

The different types of constructions were distributed as shown in Figure I:

The largest category was thus (t)here-constructions - I59/2IO or $76 \%$ of the instances where an accountable analysis was possible, and thus the type most amenable to a quantitative analysis. (T)here-constructions will therefore be the focus of our investigation.

Henceforth we will only distinguish between zero or non-zero constructions; the use of that- versus wh-relatives has been adequately treated in earlier work, such as e.g Johansson (2012), and will therefore not be discussed here. The distribution of zero relatives in (t)here-constructions is shown in Table 3 . 
Table 3. The distribution of zero subject relatives in $(t)$ here-constructions in Trials and Comedy in CED.

\begin{tabular}{|c|c|c|c|c|c|c|c|c|c|}
\hline \multicolumn{3}{|c|}{ Trials } & \multicolumn{3}{|c|}{ Comedy } & \multicolumn{4}{|c|}{ Trials+Comedy } \\
\hline I & II & III & IV & V & VI & VII & VIII & IX & $\mathrm{X}$ \\
\hline Period & $\begin{array}{l}\text { Total } \\
\text { subj rels }\end{array}$ & $\begin{array}{l}\text { N } \\
\text { ZSR }\end{array}$ & $\begin{array}{l}\% \\
\text { ZSR }\end{array}$ & $\begin{array}{l}\text { Total } \\
\text { subj rels }\end{array}$ & $\begin{array}{l}\text { N } \\
\text { ZSR }\end{array}$ & $\%$ ZSR & $\begin{array}{l}\text { Total } \\
\text { subj rels }\end{array}$ & $\begin{array}{l}\text { N } \\
\text { ZSR }\end{array}$ & $\%$ ZSR \\
\hline I & 5 & $\circ$ & ०\% & 5 & 2 & $40 \%$ & IO & 2 & $20 \%$ \\
\hline 2 & 6 & I & $17 \%$ & I7 & I3 & $76 \%$ & 23 & $\mathrm{I} 4$ & $70 \%$ \\
\hline 3 & $3 I$ & I3 & $42 \%$ & IO & 6 & $60 \%$ & $4 \mathrm{I}$ & I9 & $46 \%$ \\
\hline 4 & 36 & 4 & II $\%$ & 7 & 2 & $29 \%$ & 43 & 6 & $\mathrm{I} 4 \%$ \\
\hline \multirow[t]{2}{*}{5} & $2 I$ & 2 & IO $\%$ & $2 I$ & 7 & $33 \%$ & 42 & 9 & $2 \mathrm{I} \%$ \\
\hline & 99 & 20 & $20 \%$ & 60 & 30 & $50 \%$ & I59 & 50 & $31 \%$ \\
\hline
\end{tabular}

Table 3 shows the total number and distribution of relevant $(t)$ here constructions in the entire sub-corpus. Trials are accounted for in columns II-IV, Comedy in columns V-VII, and the entire corpus in columns VIII-X. The total proportion of ZSRs was 5 O/I 59 or $3 \mathrm{I} \%$, but notice the difference between the two genres: ZSR-constructions amount to $20 \%$ in Trials and $50 \%$ in Comedy, as appears from columns IV and VII. This discrepancy is itself an interesting finding that will be discussed in section 7.4 below.

The frequency of 50 ZSRs in there-constructions in our 524,430-word sample corresponds to 95 instances per million words (pmw). If we exclude $2 \mathrm{I}$ instances of here and consider only there-constructions, we get 29 ZSRs per 524,430 words, or 55 pmw. Lehmann's figure of I 6 ZSRs in there-constructions in the 4.2 million words of British PDE corresponds to 30 instances pmw, and his figure for American English of 27 ZSRs in there-constructions in 5 million words corresponds to 5.4 per million words - we can thus see a sharp decline in the use of ZSRs in these constructions over time. This corroborates findings reported in earlier works (e.g. Erdmann I980; Nagucka I980).

\section{Factors determining the choice of ZSRs}

After gathering the relevant data, we checked a large number of factors for their possible influence on the choice of ZSR. We first cast our net wide, including all those listed below, extra- and intra-linguistic. Only 
those marked in boldface yielded interesting results and will be discussed in detail below.

\section{EXTRALINGUISTIC}

- Sociolinguistic factors: socio-economic class and gender of speakers

- Time period

- Text type/genre - Trial or Comedy

INTRALINGUISTIC FACTORS

- Here vs. there - constructions

- Distance between head of antecedent and relativizer slot

- Antecedent number (There is someone.../there are two men...)

- Antecedent head: Indefinite noun, definite noun, pronoun, name

- Animacy of antecedent head

- Tense in matrix clause (There is, there was...)

- Verb form in relative clause - Finite, Modal, or other Auxiliary

- Polarity - positive or negative matrix clause

- Question or statement in matrix clause

- Prose or meter - convenience of zero in blank verse could be a factor

For coding, we used Goldvarb X, which is useful for establishing basic statistics even when the material inspected is too small to permit a regression analysis, as in the present case.

\section{Extralinguistic factors}

We begin with socio-economic class as a possible factor favoring ZSR, as the construction has been labeled "non-standard" by grammarians.

\subsection{Socioeconomic class}

A fine-grained analysis was not possible, but we were able to categorize most speakers as belonging to either a higher class, which we called $\mathrm{U}$ (pper class), consisting of nobility, clergymen, judges and attorneys, and a class comprising other speakers, Non-U(pper class), made up of servants, cooks, nurses and most defendants. Three individuals could not be classified, but that still left a total of ${ }_{5} 6$ speakers. As shown in Figure 2, there was no difference between U- and Non-U speakers as measured by the percentages of ZSRs - the proportion of ZSR use was 


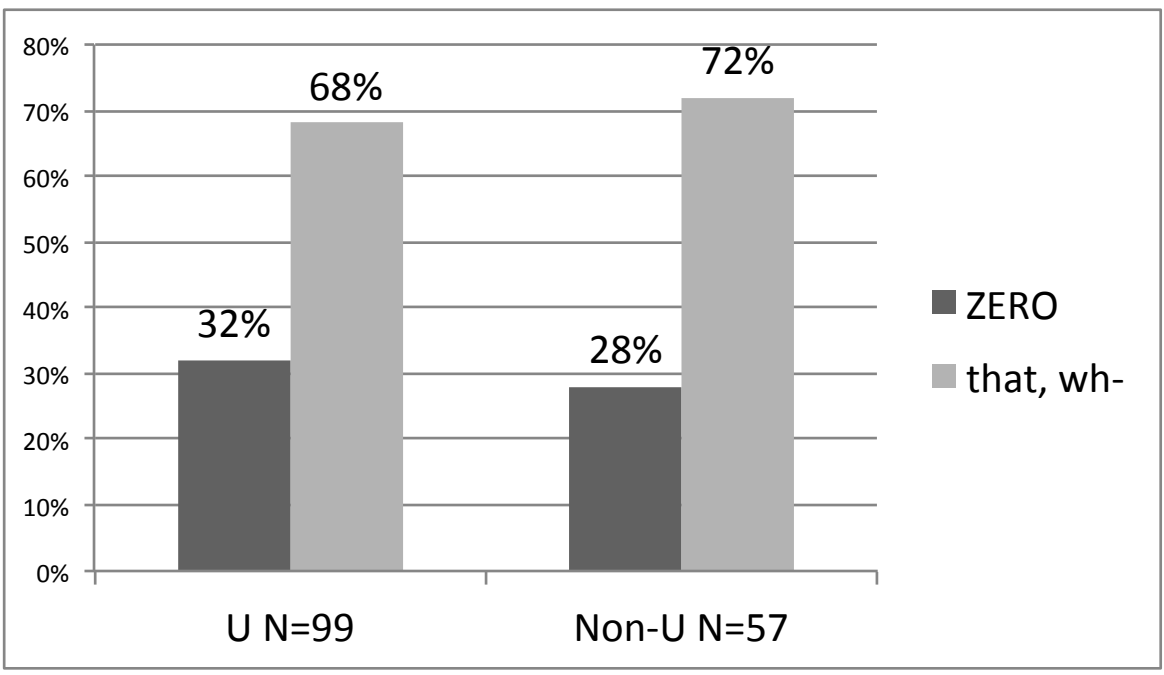

Figure 2. The distribution of ZSR and surface relativizers in the CED subsample.

roughly the same in the two samples, $32 \%$ for U speakers, and $28 \%$ for Non-U speakers.

The small difference between $U$ and Non-U speakers was not significant. It thus appears that in Early Modern English, the use of ZSRs was not a marker of socio-economic class, but that more educated speakers were as likely to use these constructions as less educated ones. Examples (9) and ( Io) are from Trials and illustrate there + ZSR with $\mathrm{U}$ and Non-U speakers, respectively.

(9) [Parson] There was a Gentleman $\varnothing$ fetch'd Me and the Clerk from the Fleet.

(Tryals of Haagen Swendsen, I702)

(Io) [Mr. Baley] My Lord, there has been at least 500 people $\varnothing$ have viewed her.

(Tryal of Mary Moders, I 663)

\subsection{Speaker gender}

Speaker gender could not be analyzed in the same way as socio-economic class, as there were only i I observations based on women speakers in the whole sub-corpus, i.e. $7 \%$ of the data, as appears from Table 4. But this in itself is an interesting fact that prompted us to investigate whether speech by women actually accounted for only $7 \%$ of the total CED sub-corpus. 
Table 4. The distribution of zero subject relatives in $(t)$ here-constructions in Trials and Comedy in CED.

\begin{tabular}{lrrr}
\hline & \multicolumn{3}{c}{ Relativizer } \\
\cline { 2 - 4 } & $\varnothing$ & that/wh- & Total \\
\hline Male speakers & 46 & \multicolumn{1}{c}{ IO2 } & I $48(93 \%)$ \\
Female speakers & 4 & 7 & I I $(7 \%)$ \\
All speakers & 50 & IO9 & I 59 (I00\%) \\
\hline
\end{tabular}

A representative sample consisting of $20 \%$ of our sub-corpus shows that women actually participated very little - the overall proportion of women's speech is about $16 \%$ in the whole material. ${ }^{4}$ There is a big difference between Trials and Comedy, however: in Comedy, women account for about $28 \%$ of all speech, and in Trials for only $4 \%$. Three texts are exceptional in having high proportions of female speech, Farquhar's The Beaux Stratagem, the Tryal of Stephen Colledge and the Tryals of Haagen Swendsen, all from Period 4. A couple of illustrative examples are (II) and (I2) from the Haagen Swendsen trials, where two women, Mrs. Rawlins and Mrs. Busby, are very talkative:

(I I) [Mrs. Busby] I'll tell you Sir, if you please, I did not know what I was Arrested for, it might be Murder or Treason for ought I knew, there was a little Boy by, $\varnothing$ said Madam I know $\mathrm{Mr}$ Unkle. (Tryals of Haagen Swendsen, I702)

(I2) [Mrs. Rawlins] It was Saturday morning before I was releas'd, there was some of my Friends $\varnothing$ came to the place where I was. (Tryals of Haagen Swendsen, I702)

Finally, because of the paucity of examples, the only conclusion to be drawn considering the importance of gender is that women seem to have used fewer subject relativizers than men overall, or $7 \%$ of the total number of relativizers produced in $16 \%$ of the total number of words, leaving plenty of room for speculation.

\footnotetext{
${ }_{4}$ A random sample consisting of $20 \%$ of each text was studied.
} 


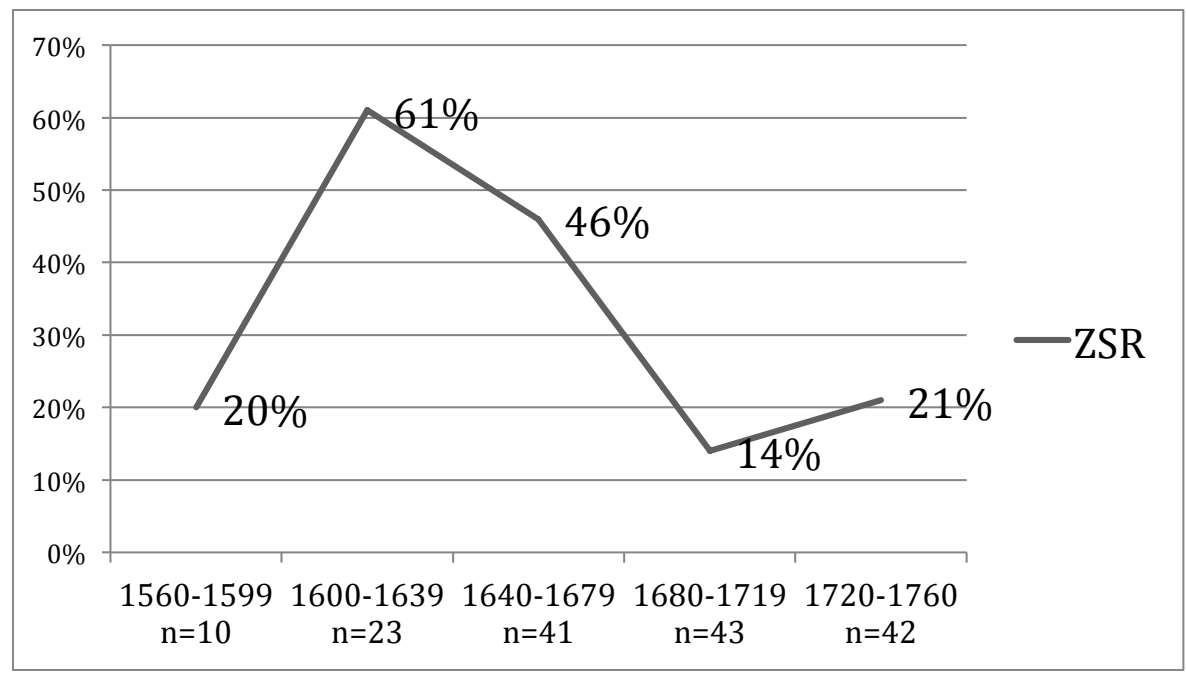

Figure 3. The distribution of ZSRs in there-constructions: Aggregate data for Trials and Comedy in Periods I-5.

\subsection{Change over time in Early Modern English}

We have seen that ZSRs have become less frequent over time, and we therefore investigated the distribution of ZSR and surface relativizers across the time period covered by CED in Figure 3 .

The data presented in Figure 3 must be analyzed with caution. Recall that the samples from the five different time periods were of very different sizes, as shown in Table I. The low number of examples from Period I, only Io, makes that data highly unreliable. Period 2 yields 23 examples even though the sample size is smaller, but only in Periods $3-5$ do we have fairly large numbers of examples, 4I, 43 and 42, respectively. Starting with period 3 (I640-I679), we see a downward trend for ZSRs; the difference between the proportions of ZSRs in Period 2 and Period 5 is significant at 0.0036 (chi-square 8.46, I d.f.), and between Period 3 and 5 at 0.0302 (chi-square 4.7, I d.f.).

\subsection{Genre: Trials and Comedy}

Moreover, the skewness of our sub-corpus makes it necessary to account for the distribution of ZSRs separately in Trials and Comedy. This is shown in Figure 4. For Period 2 the proportion $17 \%$ ZSR in Trials is based on a single instance out of six there-constructions and is thus highly uncertain. The $76 \%$ ZSR from Comedy is slightly better, but it is based on only $\mathrm{I} 3$ out of $\mathrm{I} 7$ observations. But with more data from 


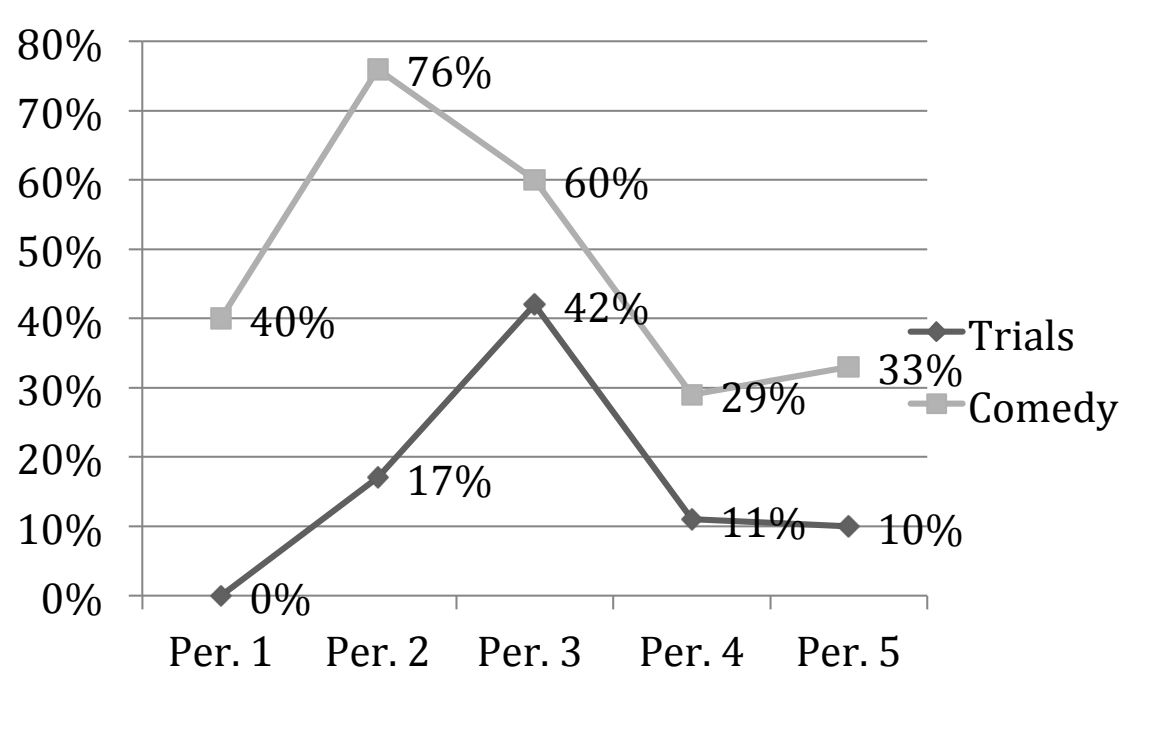

Figure 4. The distribution of ZSR over time in $(t)$ here-constructions in Trials and Comedy.

periods $3-5$, we see that the downward trends in Trials and Comedy parallel each other, and that the general tendency for ZSRs to decrease in frequency over time holds for both genres in Periods $3-5$.

\section{Intralinguistic factors}

As also shown in Table 2 above, Comedy has consistently higher frequencies of ZSRs than Trials. The question must now be why there is a difference in ZSR frequency between the two genres.

\subsection{Here and there}

We first checked the possibility of influence of meter, as blank verse might have required either a surface or a zero realization to make lines scan. That hypothesis could quickly be discarded, as there was little blank verse (or indeed other meter) in our sample, only five instances, with two zero and three surface relatives, respectively. ${ }^{5}$ Instead, we need a two-step explanation:

5 Interestingly, the vast majority of Ukaji's ZSR examples are from blank verse: only $60 / 303$, or about $20 \%$, are from prose. An accountable study would be necessary to find out what the proportions are in prose and poetry, respectively. 


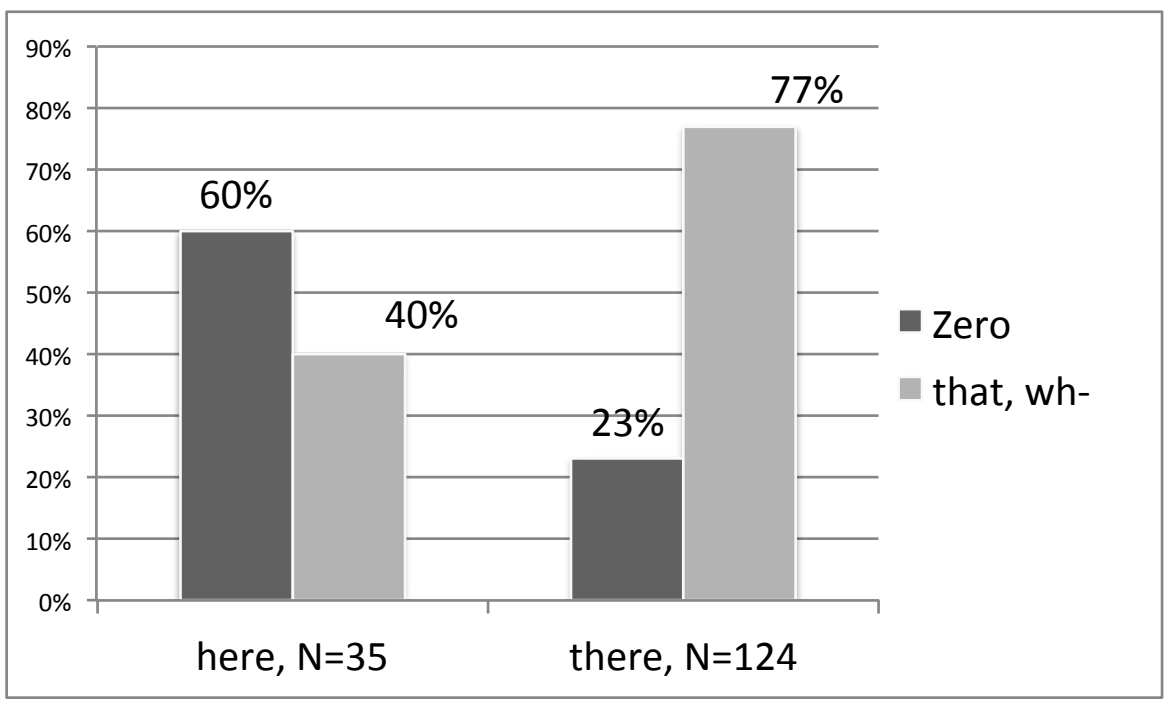

Figure 5. The use of ZSR in here- and there-constructions.

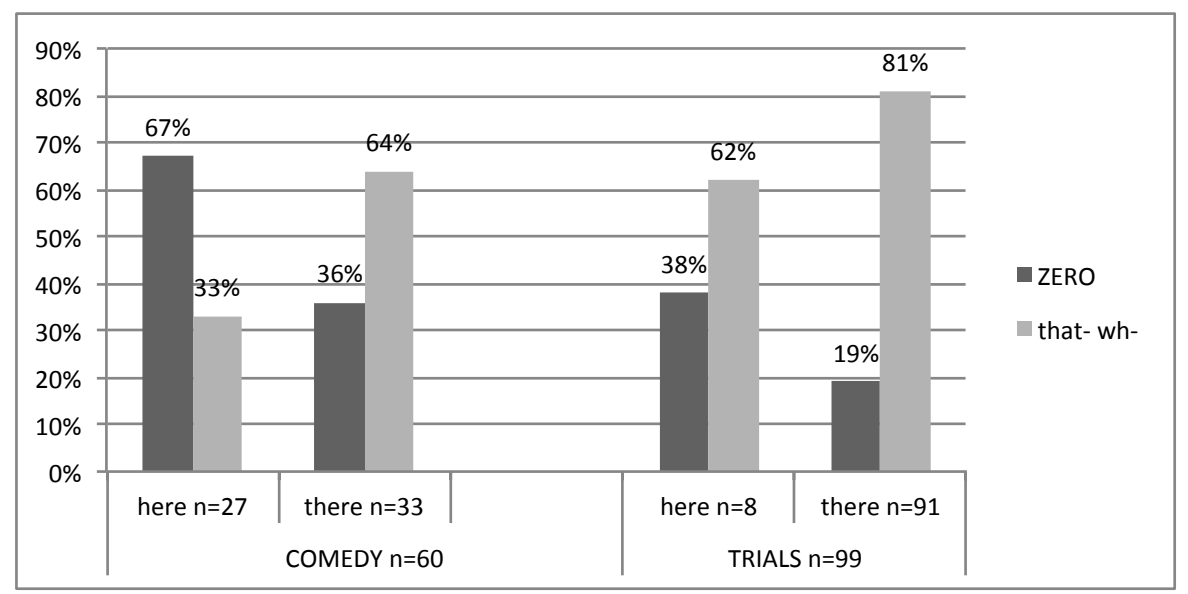

Figure 6. Here- and there-constructions in Comedy and Trials.

Firstly, here-constructions are more apt to take ZSR than there-constructions, as shown in Figure 5 and secondly, here-constructions are more frequent in Comedy than in Trials, as shown in Figure 6.

Figure 5 shows that here-constructions have $60 \%$ ZSRs, but there-constructions only $23 \%$; the difference is highly significant ( $\mathrm{p}<0.000$ I, chi-square I 5.32, I d.f.)

Furthermore, most here-constructions occur in Comedy, as shown in Figure 6: Here accounts for $27 / 33$ instances, or $45 \%$, in Comedy, but only $8 / 99$ or $8 \%$ in Trials. This difference is highly significant (p<0.000I, chi-square 27 , I d.f.). 
The fact that here-constructions, with their high proportion of ZSR, abound in Comedy thus goes a long way to explain why the ratio of ZSRs is higher in that text type.

The next question must be why here-constructions are so frequent in Comedy. The answer is supplied by the instances presented in (I3) $-\left(I_{6} 6:^{6}\right.$

(I3) [Lemot]...here is one $\varnothing$ had hanged himselfe for loue ... (George Chapman, An Humorous Dayes Myrth, I 599)

(I4) [Medley] Dorimant! you are luckily come to justify Your self — here's Lady - [Bellinda] Ø Has a word or two to say to you from a Disconsolate person.

(George Etheredge, The Man of Mode, I676)

(I 5) [Dash (servant)] Here are Gentlemen in hast Ø would speake with you.

(Lording Barrey, Ram-Alley, I6I I)

(I6) [Daffodil] My Lord Marquis, here is a Letter $\varnothing$ has started Game for you already...

(David Garrick, The Male-Coquette, I757)

Examples (I3)-(I6) show that here-constructions fulfill an important function in plays, introducing new participants or objects appearing on stage. They have mostly a locative meaning, or very occasionally, a temporal one, as in (I7):

(I7) [Galleypot] Here's a whole Morning $\varnothing$ has been thrown away...

(James Miller, The Mother-in-Law, I734)

It is clear that here and there, although they have been lumped together by earlier writers, and although they are both presentatives, have different discourse functions, with here almost invariably having a locative meaning, and there an existential one. Checking the there-instances closely, we only found five with a locative meaning, as in (I 8), but (I9) is typical:

(I 8) [Winwife] Will you see sport? looke, there's a fellow $\varnothing$ gathers vp to him, marke.

(Ben Jonson, Bartholomew Fayre, I63 I)

${ }^{6}$ There were no instances in Period 4. 


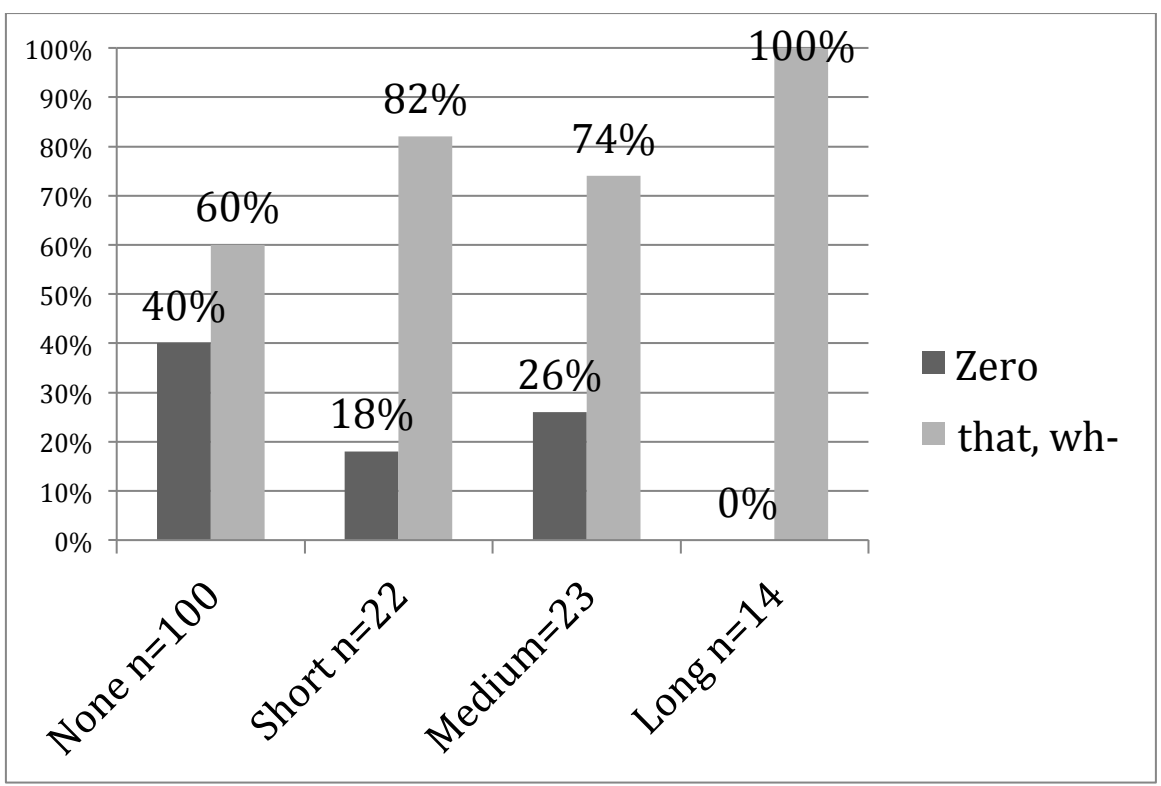

Figure 7. Distance between antecedent head and relativizer slot.

(19) [William Small-shanke] There be so many rascals, and tall yeomen $\varnothing$ VVould hang vpon me for their maintenance... (Lording Barrey, Ram-Alley, I6I I)

\subsection{Distance between antecedent head and relativizer}

The distance between the antecedent head and the relativizer slot was also a factor influencing the choice of ZSR.7 Compare e.g. (20), where there are no intervening words between Day and goes and (2I), where there are five words between Gentlemen and that:

(20) [Scrub] There's not a Day $\varnothing$ goes over his Head without Dinner or Supper in this House.

(George Farquar, The Beaux Stratagem, 1707)

(2I) [Cary] ...there are some Gentlemen at the Queens-Head at Bow that have sent me with a Letter to you...

(Tryals of Robert Green, I678)

7 Ukaji (2003:257f) discusses the adjacency requirement, i.e. the fact that a "relative pronoun is as a rule placed immediately after its antecedent NP," and he also discusses exceptions from it in his material. 
We coded instances into four categories based on the number of words intervening between the antecedent head and the relativizer slot, thus:

No distance:

Short distance: $\mathrm{I}-2$ words

Medium distance: $3-4$ words

Long distance: $\geq 5$ words

Table 5. Proportions of ZSR according to distance antecedent head - relativizer slot.

\begin{tabular}{lc}
\hline & $\%$ ZSR \\
\hline No distance $(\mathrm{N}=\mathrm{IOO})$ & $40 \%$ \\
$\mathrm{I}-4$ words distance $(\mathrm{N}=45)$ & $22 \%$ \\
$\geq 5$ words distance $(\mathrm{N}=\mathrm{I} 4)$ & $\circ \%$ \\
$(\mathrm{~N}=$ I 59) & \\
\hline
\end{tabular}

The distribution of the categories is shown in Figure 7.

We see that no distance is by far the most frequent option, and that in those cases, the proportion of ZSR is $40 \%$. With $\geq 5$ words or more between the antecedent head and the relativizer slot, ZSR goes down to $\circ \%$ in our material. ${ }^{8}$ There was little difference between the results for examples with Short and Medium distance between antecedent head and the relativizer slot ( $4 / 22$ or I $8 \%$ ZSR vs. $6 / 23$ or $26 \%$ ZSR); if those categories are conflated to one, we arrive at the distribution shown in Table 5. The distance between antecedent Head and relativizer slot is thus an important factor for the choice of the zero option.

\section{Summary and discussion}

The purpose of our paper was to describe the use of zero subject relativizers (ZSRs) in Early Modern English speech-related trials and

${ }^{8}$ ZSR is not impossible in such constructions: Cf. Shakespeare, A Winter's Tale (I, 2, I90):

And many a man there is, even at this present,

Now while I speak this, $\varnothing$ holds his wife by the arm, That little thinks she has been sluiced in's absence, And his pond fish'd by his next neighbour... 
drama (comedy) in 524,430 words taken from the Corpus of English Dialogues, CED, covering the period from I 560 to I 760 . Because of the paucity of other types (it-clefts and a few others), we focused on presentative constructions with there and here. We performed an accountable variationist study, i.e. we examined all contexts where subject relatives occurred, not just those showing the zero variant. We found that 50 out of a total of I 59 cases - 3 I \% - were ZSRs, thus a much higher proportion than those found by Lehmann (2002) for Present-Day British and American English ( $13 \%$ and $2.5 \%$, respectively).

We also checked our material for factors that might favor or disfavor the choice of the zero variant. In contrast to Present-Day English, we found that socio-economic class did not influence the choice of variant as in Present-Day English, where the use of ZSRs has been described as informal or non-standard (Huddleston \& Pullum 2002: I055; Biber et al I999: 6I9). In the EModE period, however, ZSRs are used as often by Upper as by Non-Upper class speakers. Influence of gender could not be determined because of the low proportion of female speakers. We had also suspected that meter would play a part in favoring ZSR, but we found only a few examples of verse in our material. ${ }^{9}$

We found four factors with a bearing on the choice of relativizer, viz.

Time period

Text type/genre - Trial or Comedy

Here vs. there-constructions

The distance between antecedent Head and relativizer

Our data substantiated earlier findings about the downward trend of ZSRs over time, from 6I \% in Period 2 (I600-I 639) to $21 \%$ in Period 5 (I720-I760), with some fluctuations and reservations for low data in earlier periods.

Text type was another decisive factor: Comedy has consistently higher frequencies of ZSRs than Trials, $50 \%$ vs $20 \%$ overall, with some fluctuations over time. The reason for this must be that it is in this text category that most here-constructions are found, and they are more apt to take ZSRs than there-constructions. Here-constructions serve a particular function in plays, to introduce new characters or objects, as in Here is an old mastiffe bitch $\varnothing$ stands barking at mee. They thus usually have a locative meaning, as opposed to there-constructions, which

9 However, as already pointed out above, among the 303 examples cited by Ukaji (2003) 253 were in verse; the factor obviously merits further study. 
are almost invariably existential. This in turn makes the previous joint categorization of here and there-constructions as one type questionable.

The distance between antecedent Head and relativizer slot turned out to be an important factor. First of all, most subject relative clauses with adjacent antecedent heads and relativizer slot, i.e. no distance, is by far the most frequent type: I00/I 59 instances, or $63 \%$ are of this type. Moreover, among those sentences the proportion of ZSR is $40 \%$. With a I-4 word distance, the ZSR frequency goes down to $22 \%$, and with $\geq 5$ words or more between the antecedent head and the relativizer slot, ZSRs are non-existent in our data. This is in accordance with the complexity principle postulated by Rohdenburg (I996: I 5I): "In the case of more or less explicit grammatical options the more explicit one(s) will tend to be favored in cognitively more complex environments." In relative clauses, the more explicit $w h$-forms or that are thus preferred when elements intervene between antecedent head and relative clause.

As stated earlier, we have focused on presentative constructions with $(t)$ here in our paper since this is where ZSRs are most frequent in EModE. In PDE, they occur almost exclusively in these constructions (see e.g. Quirk et al I985: I406-I407). According to van der Auwera (I984), ZSRs found in OE and ME began to disappear because English at later stages required explicit subjects, which had not been necessary as long as verbs were marked for person. ZSRs survived in pragmatically focused constructions, i.e. the presentative constructions, since there is less need for an explicit subject in these constructions (see van der Auwera I984; Dekeyser i986).

Scholars have offered different explanations why presentative there-constructions can occur without a subject. Lambrecht (I988) claims that they have to be without a subject in order to express the information as one grammatical unit, which is probably how they occur in discourse (presentative amalgam constructions, Lambrecht I988: 336). Diessel (2004) sees ZSRs in there-constructions and in other contexts as precursors of relative clauses with surface relativizers in $\mathrm{LI}_{\mathrm{I}}$ acquisition, which appear with increasing frequency as children are exposed to more adult speech and become literate. Literacy also seems to have a great deal to do with the fact that ZSRs are found in Present-day English dialects without written records and in substandard varieties used by speakers with little knowledge or use of written language. In the standard language, it is possible that ZSRs and there are learned as one construction or chunk and that ZSRs survive 
in impromptu speech because of the frequency of there-constructions of which they are a part (cf. Bybee 20I0: I 56, I 59).

The explanations sketched above as to why ZSRs have survived in there-constructions are of course not mutually exclusive; rather they support each other. We will explore these explanations and others in more detail in further work.

\section{References}

Biber, D., Johansson, S., Leech, G., Conrad, S., \& Finegan, E. (1999). Longman Grammar of Spoken and Written English. Harlow: Longman.

Bybee, J. (2010). Language, Usage and Cognition. Cambridge: Cambridge University Press.

Culpeper, J., \& Kytö, M. (2010). Early Modern English Dialogues. Cambridge: Cambridge University Press.

Dekeyser, X. (1984). Relativizers in Early Modern English. A dynamic quantitative Study. J. Fisiak (ed.), Historical Syntax. Berlin: Mouton, 6I-87.

Dekeyser, X. (1986). English contact clauses revisited. Folia Linguistica Historica 7, I07-I 20.

Diessel, H. (2004). The Acquisition of Complex Sentences. Cambridge: Cambridge University Press.

Erdmann. P. ( 1980 ). On the history of subject contact-clauses in the history of English. Folia Linguistica Historica I, I39-I70.

Hackenberg, R.H. (1972). Appalachian English: a sociolinguistic study. Unpublished $\mathrm{PhD}$ thesis. Georgetown University.

Huddleston, R. \& Pullum, G. K. (2002). The Cambridge Grammar of the English Language. Cambridge: Cambridge University Press.

Ihalainen, O. (1980). Relative clauses in the dialect of Somerset. Neuphilologische Mitteilungen 8I, I87-I96.

Jespersen, O. (1927). A Modern English Grammar on Historical Principles. Part 3. Copenhagen: Munksgaard.

Johansson, C. (20I2). Relativization in Early Modern English: Written versus speech-related genres. L. Brinton \& A. Bergs (eds) English Historical Linguistics: An International Handbook, Vol. I. Berlin: Mouton, $776-790$.

Kortmann, B. \& Schneider, E. (eds) (2004). A Handbook of Varieties of English: A Multimedia Reference Tool. Berlin: Mouton.

Kytö, M. \& Walker, T. (2006). Guide to A Corpus of English Dialogues I560-I760. Acta Universitatis Upsaliensis. Studia Anglistica Upsaliensia I 30. 
Lambrecht, K. (1988). There was a farmer had a dog: Syntactic amalgams revisited. Paper presented at the Berkeley Linguistics Society. Proceedings of the Fourteenth Annual Meeting, 319-339.

Lehmann, H.-M. (2002). Zero subject relative constructions in American and British English. P. Peters (ed.), New Frontiers of Corpus Research. Amsterdam and New York: Rodopi, I63-I77.

Nagucka, R. (I980). Grammatical pecularities of the contact-clause in EModE. Folia Linguistica Historica I, I7 I-I84.

Quirk, R., Greenbaum, S., Leech, G. \& Svartvik, J. (I985). A Comprehensive Grammar of the English Language. London: Longman.

Rohdenburg, G. (1996). Cognitive complexity and increased grammatical explicitness in English. Cognitive Linguistics 7:I49-I 82.

Romaine, S. (I98I). The relative clause marker in Scots English: Diffusion, complexity and style as dimensions of syntactic change. Language in Society 9: $22 \mathrm{I}-247$.

Rydén, M. (1966). Relative Constructions in Early Sixteenth Century English. With Special Reference to Sir Thomas Elyot. Acta Universitatis Upsaliensis. Studia Anglistica Upsaliensia 3.

Shnukal, A. (I98I). There's a lot mightn't believe this...variable subject relative pronoun absence in Australian English. D. Sankoff \& H. Cedergren (eds) Variation Omnibus. Edmonton, Alberta: Linguistic Research, $32 \mathrm{I}-328$.

Tottie, G. (I997). Relatively speaking. Relative marker usage in the British National Corpus. T. Nevalainen \& L. Kahlas-Tarkka (eds) To Explain the Present: Studies in the Changing English Language in Honour of Matti Rissanen. Helsinki: Société Néophilologique, 465-48I.

Ukaji, M. (2003). Subject zero relatives in Early Modern English. M. Ike-uchi, M. Ukaji, \& Y. Nishimura (eds) Current Issues in English Linguistics Tokyo: Kaitakusha, 248-277.

van den Eynden, N. (I993). Syntactic Variation and Unconscious Linguistic Change. A Study of Adjectival Relative Clauses in the Dialect of Dorset. Frankfurt a. M.: Peter Lang.

van der Auwera, J. (1984). More on the history of subject contact clauses in English. Folia Linguistica Historica 5, I70-183. 